\title{
Erratum to: Permeability Changes of Manduca sexta Midgut Brush Border Membranes Induced by Oligomeric Structures of Different Cry Toxins
}

\author{
C. Muñoz-Garay $\cdot$ J. Sánchez $\cdot$ A. Darszon · \\ R. A. de Maagd $\cdot$ P. Bakker $\cdot$ M. Soberón $\cdot$ \\ A. Bravo
}

Published online: 13 November 2012

(c) Springer Science+Business Media New York 2012

\section{Erratum to: J Membrane Biol (2006) 212:61-68 \\ DOI 10.1007/s00232-006-0003-8}

Recently in a review of our papers we found that Panels A and B of Fig. 5 were edited with Photoshop. The published figures did not made clear that they were merged figures, since some lanes of these figures came from different gels. New Fig. 5 constructed with the original gels are given below. This should be considered as definitive by the reader.

The online version of the original article can be found under doi: 10.1007/s00232-006-0003-8.

C. Muñoz-Garay · J. Sánchez · A. Darszon · M. Soberón · A. Bravo $(\bowtie)$

Instituto de Biotecnología, Universidad Nacional Autónoma de México, Apdo postal 510-3, Cuernavaca, Morelos 62250,

México

e-mail: bravo@ibt.unam.mx

R. A. de Maagd · P. Bakker

Plant Research International, P.O. Box 16, 6700 AA

Wageningen, The Netherlands

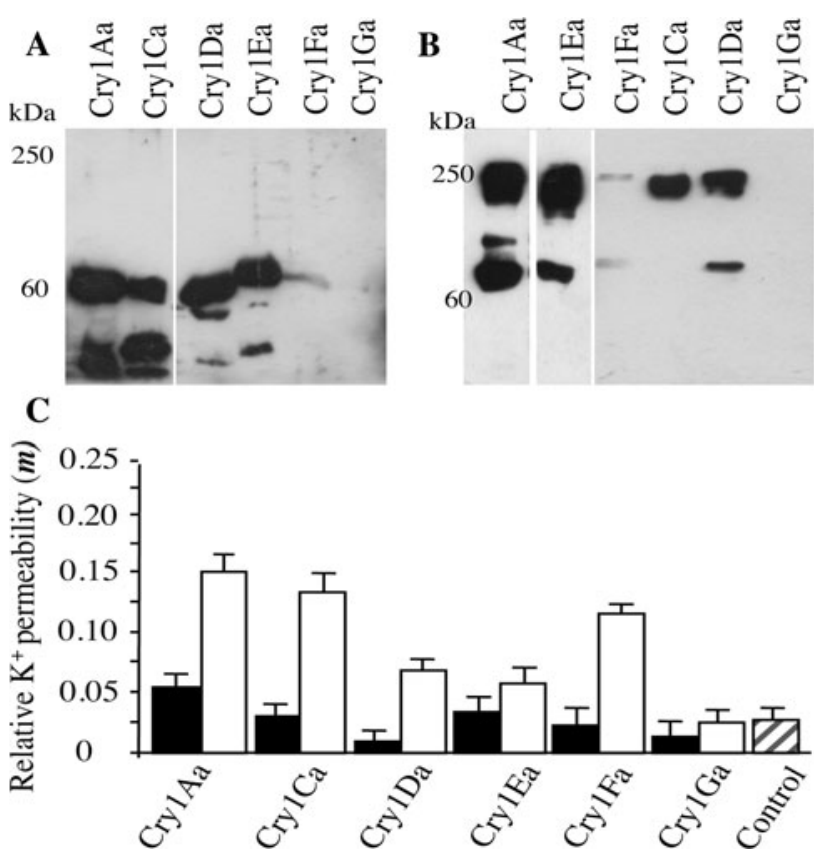

Fig. 5 Activation and pore-formation activity of different Cry1 toxins. Western blot analysis of the different Cry1 toxins activated with trypsin, showing only $60-\mathrm{kDa}$ monomeric toxin and some small bands produced by toxin degradation. a Western blot of the monomeric and oligomeric structures of the different Cryl toxins obtained after activation with $M$. sexta BBMVs. b Relative $\mathrm{K}^{+}$permeability $(m)$ of toxin samples activated with BBMVs (white bars, $1.4 \mu \mathrm{g}$ ) and their corresponding trypsin-activated toxin (black bars, $1.4 \mu \mathrm{g})(\mathbf{c})$ 